\title{
Electron Detachment Dissociation of Glycosaminoglycan Tetrasaccharides
}

\author{
Jeremy J. Wolff and I. Jonathan Amster \\ Department of Chemistry, University of Georgia, Athens, Georgia, USA
}

\author{
Lianli Chi and Robert J. Linhardt \\ Department of Chemistry and Chemical Biology, Chemical and Biological Engineering, and Biology, \\ Rensselaer Polytechnic Institute, Troy, New York, USA
}

\begin{abstract}
The first application of electron detachment dissociation (EDD) to carbohydrates is presented. The structural characterization of glycosaminoglycan (GAG) oligosaccharides by mass spectrometry is a longstanding problem because of the lability of these acidic, polysulfated carbohydrates. Doubly-charged negative ions of four GAG tetrasaccharides are examined by EDD, collisionally activated dissociation (CAD), and infrared multiphoton dissociation (IRMPD). EDD is found to produce information-rich mass spectra with both cross ring and glycosidic cleavage product ions. In contrast, most of the product ions produced by CAD and IRMPD result from glycosidic cleavage. EDD shows great potential as a tool for locating the sites of sulfation and other modifications in glycosaminoglycan oligosaccharides. (J Am Soc Mass Spectrom 2007, 18, 234-244) @ 2007 American Society for Mass Spectrometry
\end{abstract}

$\mathrm{G}$ lycosaminoglycans (GAGs) are linear, polydisperse, sulfated polysaccharides found in a wide variety of organisms, from bacteria to humans [1]. GAGs play an important role in many biological processes such as cell-cell signaling [2], the regulation of biochemical pathways [3,4], and inflammation reactions [5]. GAGs form the carbohydrate portion of proteoglycans, which are high molecular weight (up to and $>1 \mathrm{MDa}$ ) molecules of high complexity. GAGs are composed of a repeating disaccharide of an acidic sugar and an amino sugar, and exhibit complexity through the degree and sites of sulfation in each disaccharide unit, functionalization of the amino group in the glucosamine residues, and chirality of the $\mathrm{C} 5$ carbon on the hexuronic acid residues. Additional complexity arises at the proteoglycan level from the distribution of GAG chains that bind to the core proteins.

Heparin and heparan sulfate (HS) are the most structurally complex GAGs [6]. They consist of 1,4linked repeating disaccharide of hexuronic acid and glucosamine. The hexuronic acid is either glucuronic (GlcA) or iduronic acid (IdoA), and may be sulfated at the hydroxyl group on carbon $\mathrm{C} 2$. The glucosamine $(\mathrm{GlcN})$ may be sulfated at the hydroxyl group at carbon C3 or C6, and may be unmodified, acetylated, or sulfated at the amino group on carbon C2. Determining the pattern of modification (sulfation, $\mathrm{N}$ acetylation, GlcA versus IdoA) in heparin/HS polysaccharides is of significant interest as their biological

Published online October 30, 2006

Address reprint requests to Dr. I. J. Amster, Department of Chemistry, University of Georgia, Athens, GA 30602, USA. E-mail: jamster@uga.edu activities are believed to be controlled by the pattern of modification [7-9].

Tandem mass spectrometry (MS/MS) is an excellent tool for characterizing the structure of biomolecules since it is rapid, versatile, and sensitive. However, the application of MS/MS to sulfated GAGs has been hindered by their large size, sulfation heterogeneity, and the lability of the sulfate groups, particularly during ion activation [10]. GAGs have been ionized by fast atom bombardment (FAB) [11, 12], electrospray ionization (ESI) [13], and matrix assisted laser desorption/ionization (MALDI) [14-17]. Analysis of sulfated GAGs by FAB is relatively uninformative due to the abundant loss of $\mathrm{NaSO}_{3}$ and $\mathrm{SO}_{3}$ from the singly-charged precursor ions. Ion activation by collisionally activated dissociation (CAD) or infrared multiphoton dissociation (IRMPD) of singlycharged sulfated GAGs results in abundant loss of $\mathrm{SO}_{3}$, frustrating efforts to determine sites of sulfation. ESI is the preferred ionization technique for retaining the labile sulfate groups. During MS/MS, $\mathrm{SO}_{3}$ loss can be minimized and glycosidic cleavages maximized if the charge on the ion is equal to the number of sulfate groups [18]. However, the lack of significant cross ring cleavages makes it difficult to determine the site of modification within each saccharide ring.

To increase the structural information that can be derived by mass spectrometry, a number of techniques have been investigated. Sulfated oligosaccharides have been derivatized by permethylation [19]. Localization of the site of sulfation is then determined from MS/MS of the permethylated oligosaccharides. Small oligosaccha- 

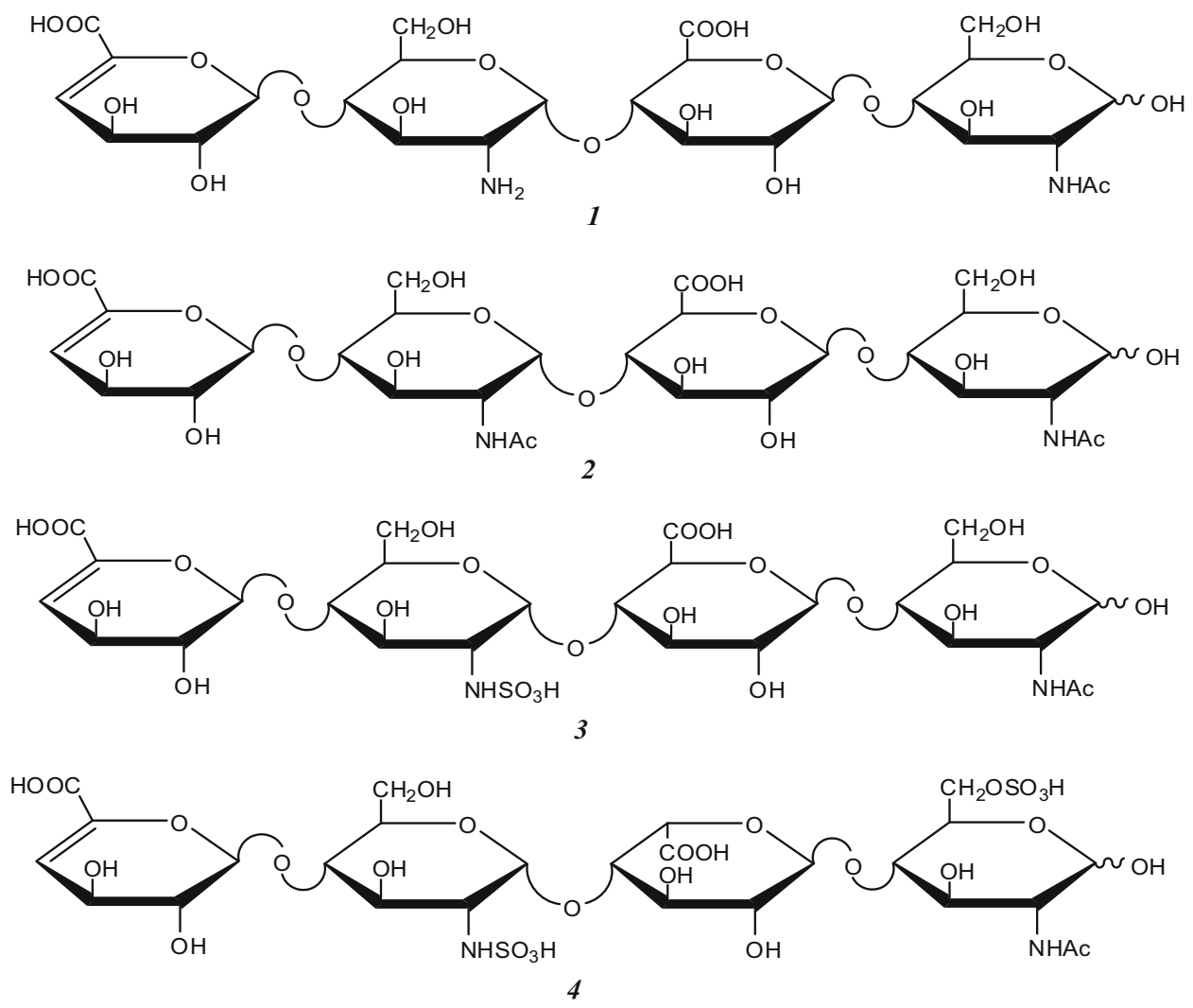

Structure 1

ride sequences can be determined by a combination of enzymatic digestion, $\mathrm{MS}^{n}$ of the disaccharides, and database searching [20]. Capillary electrophoresis has been combined with MS/MS to sequence a complex mixture [21]. These methods do not provide sufficient cross-ring fragmentation to determine the pattern of sulfation, acetylation, and hexuronic acid stereochemistry on a GAG oligosaccharide. There is thus great interest in applying novel ion activation methods to advance the MS/MS analysis of sulfated carbohydrates.

Ion activation by electrons is finding widespread application to biomolecule structure analysis. First re- ported in 1998, electron capture dissociation (ECD) is an ion activation method in which an odd-electron ion is formed by the recombination of a multiply-charged positive ion with a low-energy $(<1 \mathrm{eV})$ electron [22]. Informative fragment ions result from the dissociation of the odd-electron ion. An intriguing aspect of ECD is that it is believed to be nonergodic [23]. For example, it promotes extensive fragmentation of peptide backbones without loss of labile post-translational modifications such as glycosylation or phosphorylation [24, 25]. Positively-charged oligosaccharides have been dissociated by ECD [26]. Due to the acidic nature of sulfated

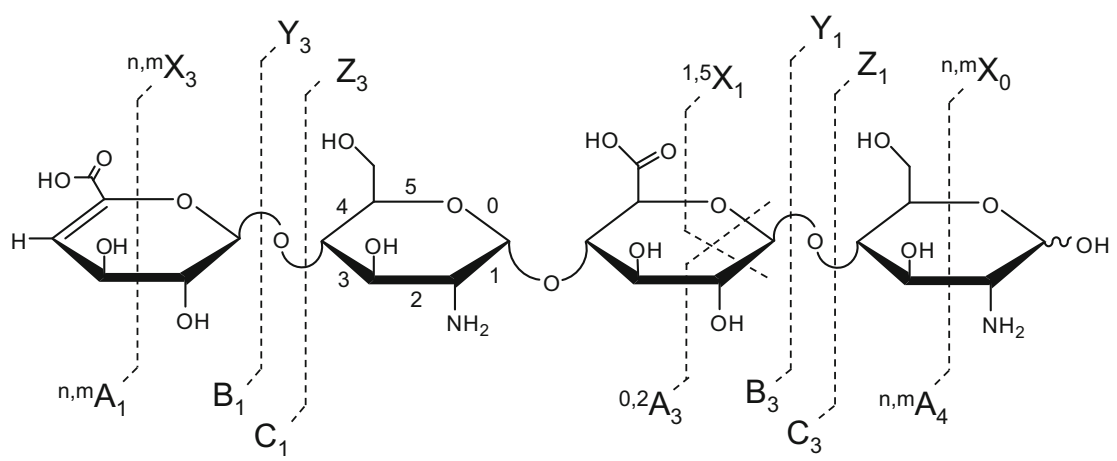

Figure 1. Fragment ion naming convention used in this paper, adapted from Domon and Costello [37]. Superscripts in cross ring cleavage products refer to the bonds that are broken, which are numbered as shown for the second saccharide from the nonreducing end. 


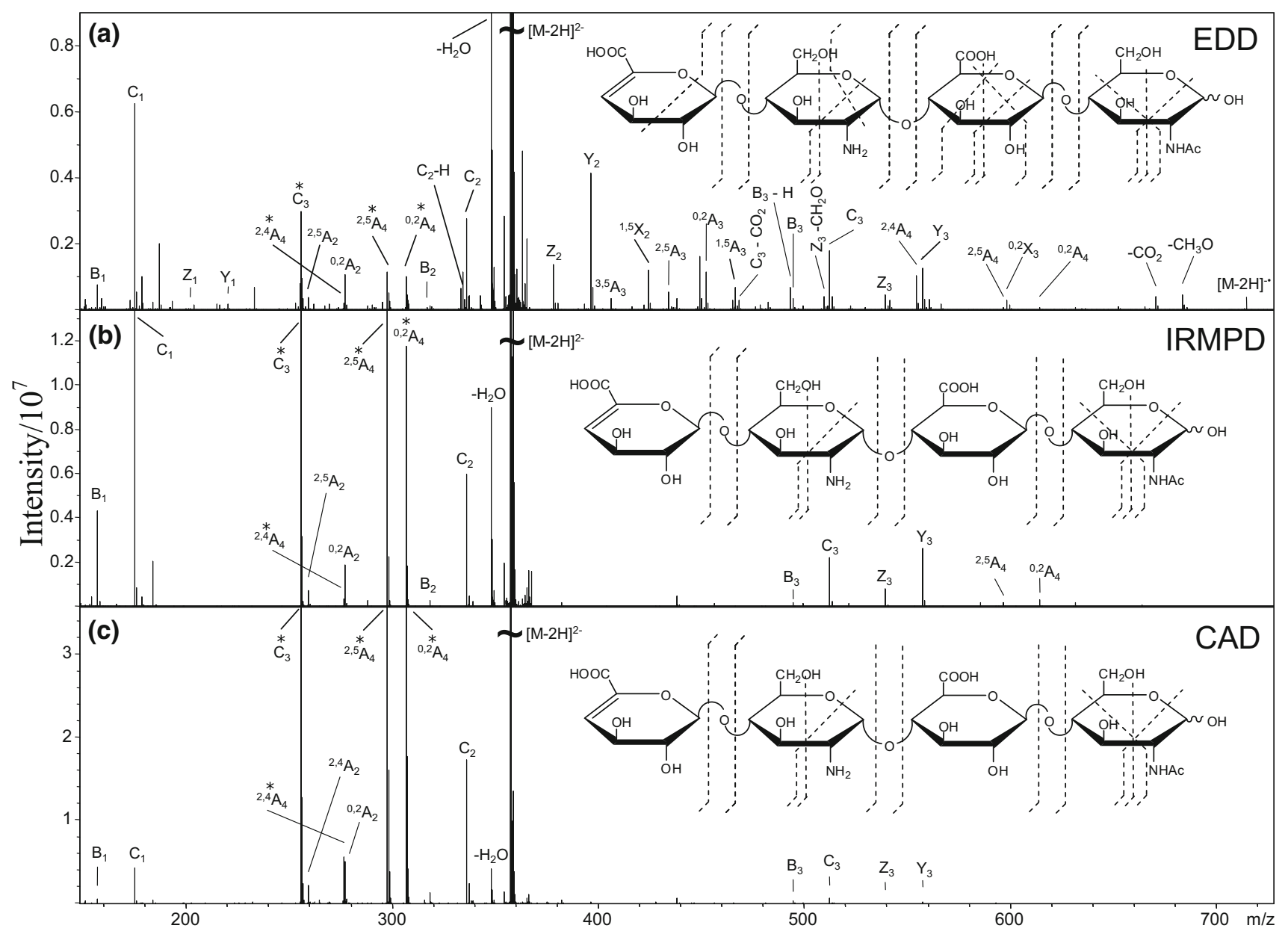

Figure 2. Tandem mass spectra of the $[\mathrm{M}-2 \mathrm{H}]^{2-}$ precursor ion of tetrasaccharide 1 , obtained by using (a) EDD, (b) IRMPD, and (c) CAD. Doubly-charged product ions are indicated with an asterisk.

GAGs, the formation of multiply-charged positive ions is difficult. We have recently obtained results for the ECD analysis of sulfated GAGs (manuscript in preparation), but find that this approach is not widely applicable because of the difficulty of forming multiplycharged positive ions for these acidic molecules.

Given the propensity of GAGs to form negative ions, we have explored the application of electron detachment dissociation (EDD) for the fragmentation of multiply-charged negative ions of some model GAG tetrasaccharides. EDD is the negative ion complement of ECD [27]; although electron detachment can be achieved in high-energy collisions with inert gases [28], it is more easily accomplished by irradiating a multiply charged negative ion with electrons of moderate kinetic energy ( 15 to $20 \mathrm{eV}$ ), causing electron detachment and leading to ion fragmentation [29-34]. This technique has been applied principally to peptides [29-32], but also to other compounds that can form negative ions, specifically nucleotides [34] and a ganglioside [33], but otherwise there are very few reports of EDD in the literature. Here, we present the first examples of the application of EDD to the analysis of GAG tetrasaccharides.

\section{Experimental}

\section{Preparation of Heparan Sulfate Tetrasaccharides}

Heparan sulfate sodium salt was obtained from Celsus Laboratories (Cincinnati, $\mathrm{OH}$ ). The heparan sulfate was digested with heparinase II (Sigma, St. Louis, MO) and fractionated by gel-permeation chromatography using a P-10 column (Bio-Rad, Hercules, CA) to obtain uniform sized oligosaccharides. The fraction containing tetrasaccharides was desalted on a Bio-Rad P-2 column and concentrated by freezedrying. Fractions containing individual tetrasaccharides were collected from semi-preparative SAXHPLC (Shimadzu, Columbia, MD) using a Spherisorb column (Waters Corp, Milford, MA), desalted on a Bio-Rad P-2 column, and freeze-dried [35]. The structure of the three tetrasaccharides (Structures 1, 2, and 4 ) and were determined by $1 \mathrm{D}$ and $2 \mathrm{D}$ proton NMR. Tetrasaccharide 3 was prepared from tetrasaccharide 1 by $N$-sulfonation using the following protocol: 50 $\mu \mathrm{g}$ of tetrasaccharide 1 was dissolved in $12.5 \mu \mathrm{L}$ of solution containing $10 \mathrm{mg} / \mathrm{mL}$ sodium bicarbonate and $10 \mathrm{mg} / \mathrm{mL}$ trimethylamine-sulfurtrioxide com- 


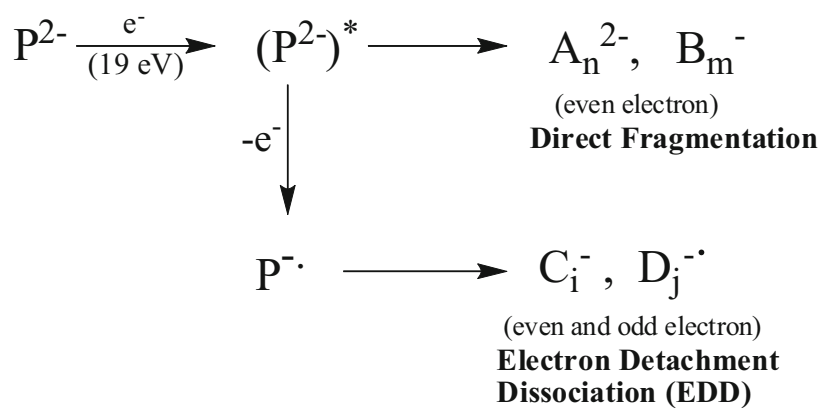

Scheme 1

plex and incubated at $50{ }^{\circ} \mathrm{C}$ for $12 \mathrm{~h}$. Equal portions of sodium bicarbonate and trimethylamine-sulfurtrioxide complex were added two more times at $12 \mathrm{~h}$ intervals. The solution was then desalted by a P-2 spin column (Bio-Rad) and the product was freezedried $^{\circ}[36]$.

\section{Mass Spectrometry Analysis}

Experiments were performed with a $7 \mathrm{~T}$ Bruker Apex IV QeFTMS (Billerica, MA) fitted with an Apollo II ESI source, a $\mathrm{CO}_{2}$ laser for infrared multiphoton dissociation (IRMPD), and an indirectly heated hollow cathode for generating electrons for ECD and EDD. The hollow cathode implementation with the Infinity ${ }^{\circ}$ cell ${ }^{\circ}$ has been ${ }^{\circ}$ previously ${ }^{\circ}$ described $^{\circ}[34] .{ }^{\circ}$ Solutions of each tetrasaccharide were made at a concen- tration of $0.1 \mathrm{mg} / \mathrm{mL}$ in 50:50 methanol: $\mathrm{H}_{2} \mathrm{O}$ (Sigma, St. Louis, MO) and ionized by nanospray using a pulled fused silica tip (model \# FS360-75-15-D-5, New Objective, Woburn, MA). The sample solutions were infused at a rate of $10 \mu \mathrm{L} / \mathrm{h}$. All tetrasaccharides were examined in negative ion mode.

For the EDD experiments, precursor ions were isolated in the external quadrupole and accumulated for 1 to $2 \mathrm{~s}$ before injection into the FTMS cell. The isolation/cell fill was repeated up to six times. The selection of the precursor ion was further refined by using in-cell isolation with a coherent harmonic excitation frequency (CHEF) event. The precursor ions were then irradiated with electrons for $1 \mathrm{~s}$. For electron irradiation the cathode bias was set to $-19 \mathrm{~V}$, the ECD lens was set to $-17.5 \mathrm{~V} \pm 0.5 \mathrm{~V}$, and the cathode heater was set to 5 to $6 \mathrm{~V}$. Twenty-four acquisitions were signal averaged per mass spectrum. For each mass spectrum, $512 \mathrm{k}$ points were acquired, padded with one zero fill, and apodized using a sinebell window. Background spectra were acquired by leaving all parameters the same but setting the cathode bias to $0 \mathrm{~V}$ to ensure that no electrons reached the analyzer cell. External calibration produced mass accuracy of $5 \mathrm{ppm}$. Internal calibration was also performed using confidently assigned glycosidic bond cleavage products as calibrants, and produced mass accuracy of $1 \mathrm{ppm}$. All EDD products are reported using the Domon and Costello nomenclature, ${ }^{\circ} a^{\circ}$ shown $^{\circ}$ in $^{\circ}$ Figure $^{\circ} 1^{\circ}[37]$.
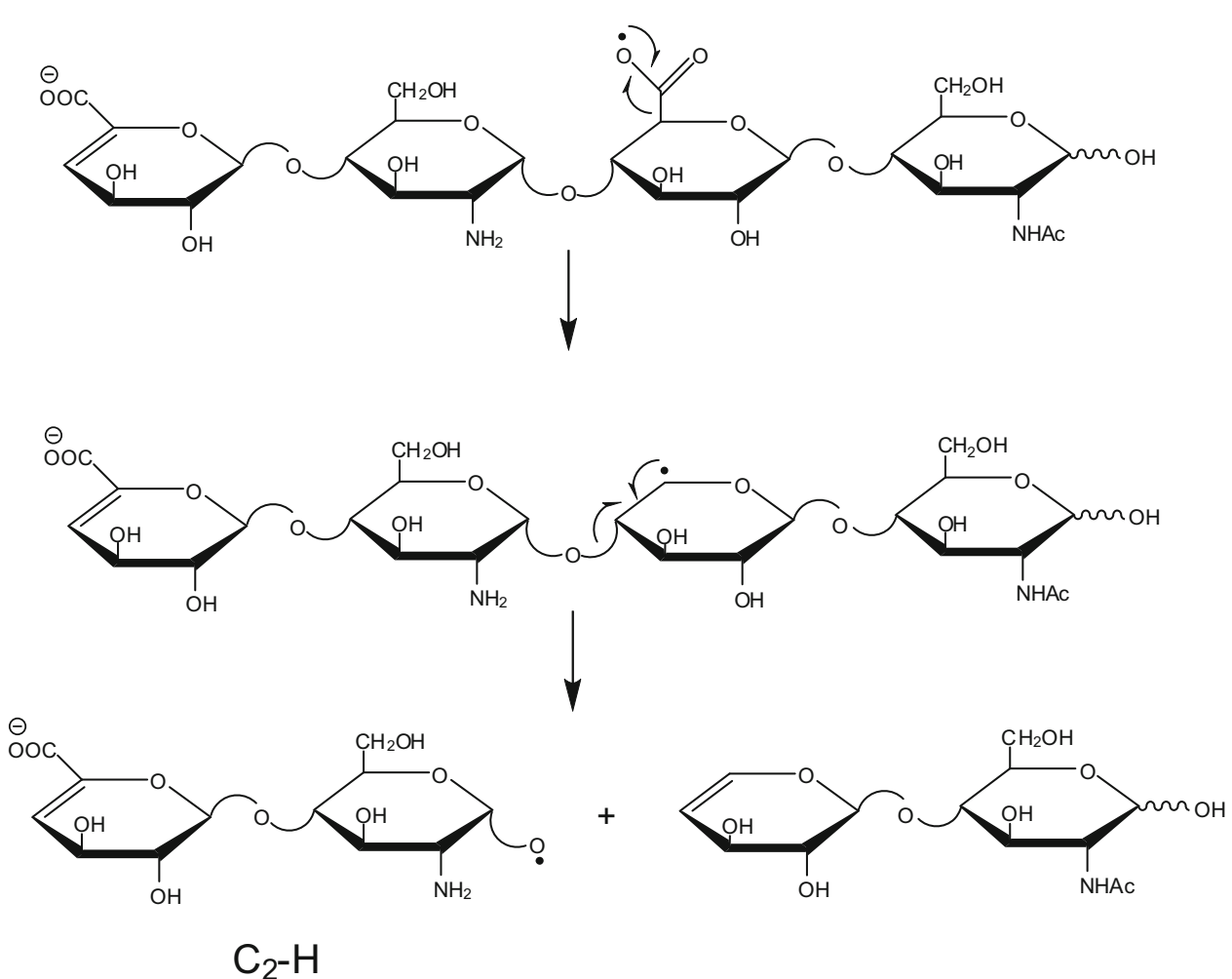

Scheme 2 


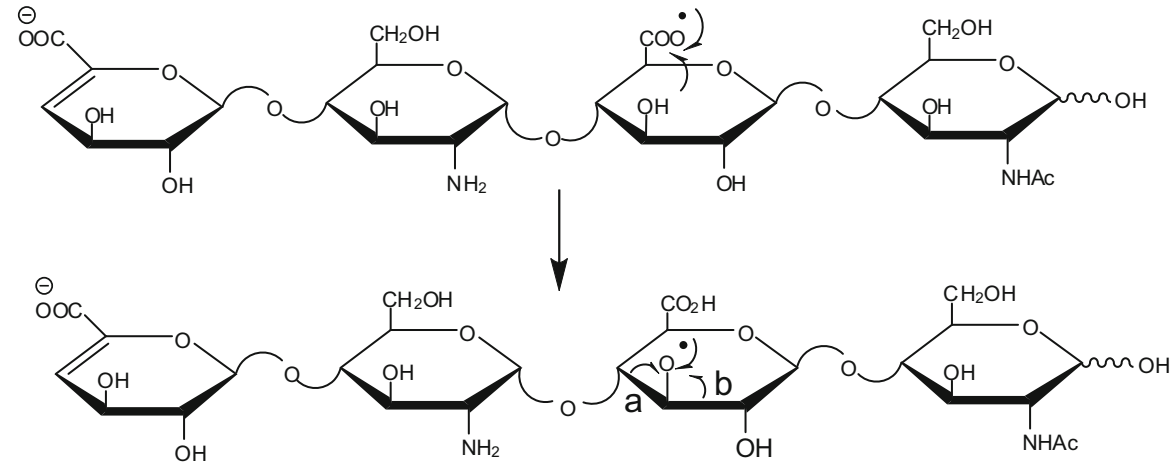

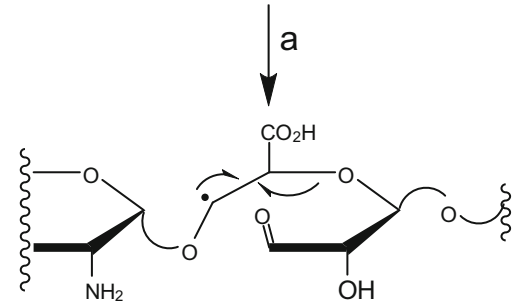

$\downarrow$

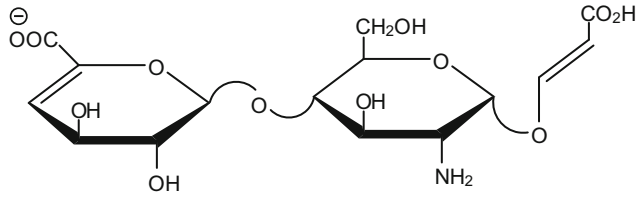

${ }^{3,5} \mathrm{~A}_{3}$

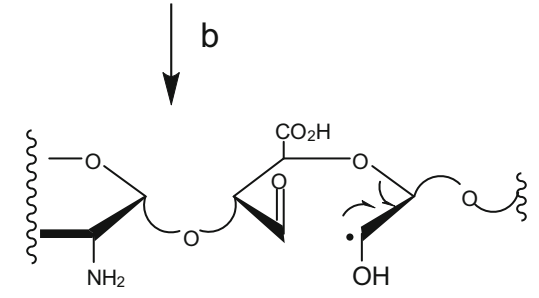

$\downarrow \begin{aligned} & \text { H-transfer } \\ & \text { to ion }\end{aligned}$

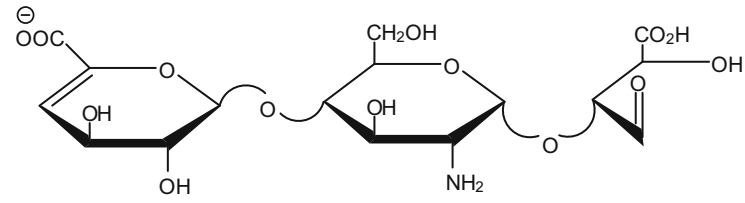

${ }^{0,2} \mathrm{~A}_{3}$

Scheme 3

\section{Results and Discussion}

Irradiation of $\Delta \mathrm{UA}-$ GlcN-GlcA-GlcNAc, 1, with $19 \mathrm{eV}$ electrons ${ }^{\circ}$ produces ${ }^{\circ}$ the ${ }^{\circ}$ mass $^{\circ}$ spectrum ${ }^{\circ}$ shown $^{\circ}$ in ${ }^{\circ}$ Figure 2a. ${ }^{\circ}$ The ${ }^{\circ}$ mass $^{\circ}$ spectrum ${ }^{\circ}{ }^{\circ}$ ontains ${ }^{\circ}$ mostly ${ }^{\circ}$ singly-charged product ions, including the charged reduced precursor, $[\mathrm{M}-2 \mathrm{H}]^{--}$, as well as a few doubly-charged products. The efficiency of product ion conversion (the sum of product ion intensities divided by the precursor ion intensity measured before irradiation, as proposed by Gorshkov ${ }^{\circ} t^{\circ}$ al. $\left.{ }^{\circ}[38]\right)^{\circ}$ is $^{\circ} \sim 6 \%{ }^{\circ}{ }^{\circ}$ The ${ }^{\circ}$ presence ${ }^{\circ}$ of ${ }^{\circ}$ both ${ }^{\circ}$ the doubly-charged product ions and the charge reduced precursor ion in the product ion spectrum indicates that products are formed via two fragmentation pathways, as shown in Scheme 1. Irradiation of the doublycharged precursor ion with $19 \mathrm{eV}$ electrons leads to an activated ion, which can undergo direct decomposition to yield even-electron product ions that are doubly- or singly-charged. For example, direct decomposition of the doubly-charged precursor produces doublycharged products such as $\mathrm{C}_{3}{ }^{2-},{ }^{2,4} \mathrm{~A}_{4}{ }^{2-},{ }^{2,5} \mathrm{~A}_{4}{ }^{2-}$, and ${ }^{0,2} \mathrm{~A}_{4}{ }^{2-}$. Alternatively, the activated precursor can lose an electron to form an odd-electron ion that undergoes further fragmentation to form singly-charged even- and odd-electron product ions. The charge-reduced molecular ion, $[\mathrm{M}-2 \mathrm{H}]^{-}$, and other odd-electron species such as $\left[\mathrm{M}-2 \mathrm{H}-\mathrm{CO}_{2}\right]^{-\cdot}$ provide direct evidence of electron detachment.

While doubly-charged product ions must arise via direct decomposition, and singly-charged odd-electron product ions must arise from electron detachment, singly-charged even-electron products can be formed by either dissociation pathway. To develop a correlation between molecular structure and fragmentation behavior, it is important to distinguish the dissociation pathways. The singly-charged even-electron products that arise from direct fragmentation of the doublycharged negative ion can be identified by using IRMPD or CAD for ion activation, as their ions are produced by dissociation of an even-electron precursor. IRMPD of 1 produces ${ }^{\circ}$ the ${ }^{\circ}$ mass $^{\circ}$ spectrum ${ }^{\circ}$ shown ${ }^{\circ}{ }^{\circ}{ }^{\circ}$ Figure $2 \mathrm{~b}$, ${ }^{\circ}$ while $\mathrm{CAD}^{\circ} \mathrm{of}^{\circ} 1$ produces $^{\circ}$ the ${ }^{\circ}$ mass $^{\circ}$ spectrum ${ }^{\circ}$ shown ${ }^{\circ}{ }^{\circ}{ }^{\circ}$ Figure 1c. ${ }^{\circ}$ The ${ }^{\circ}$ major ${ }^{\circ}$ fragments ${ }^{\circ}$ in ${ }^{\circ}$ Figure $^{\circ} 2 b^{\circ}$ and ${ }^{\circ} \mathrm{c}^{\circ}$ are ${ }^{\circ}$ principally from glycosidic bond cleavages (B, C, Y, and Z) and a few cross ring cleavages in the form of ${ }^{0,2} \mathrm{~A}_{4}$ and ${ }^{2,5} \mathrm{~A}_{4}$. Such cleavages have been observed in the CAD mass $^{\circ}$ spectra $^{\circ}$ of $^{\circ} \mathrm{GAG}^{\circ}$ of $^{\circ}$ di- $^{\circ}$ and $^{\circ}$ tetrasaccharides ${ }^{\circ}[39$, 

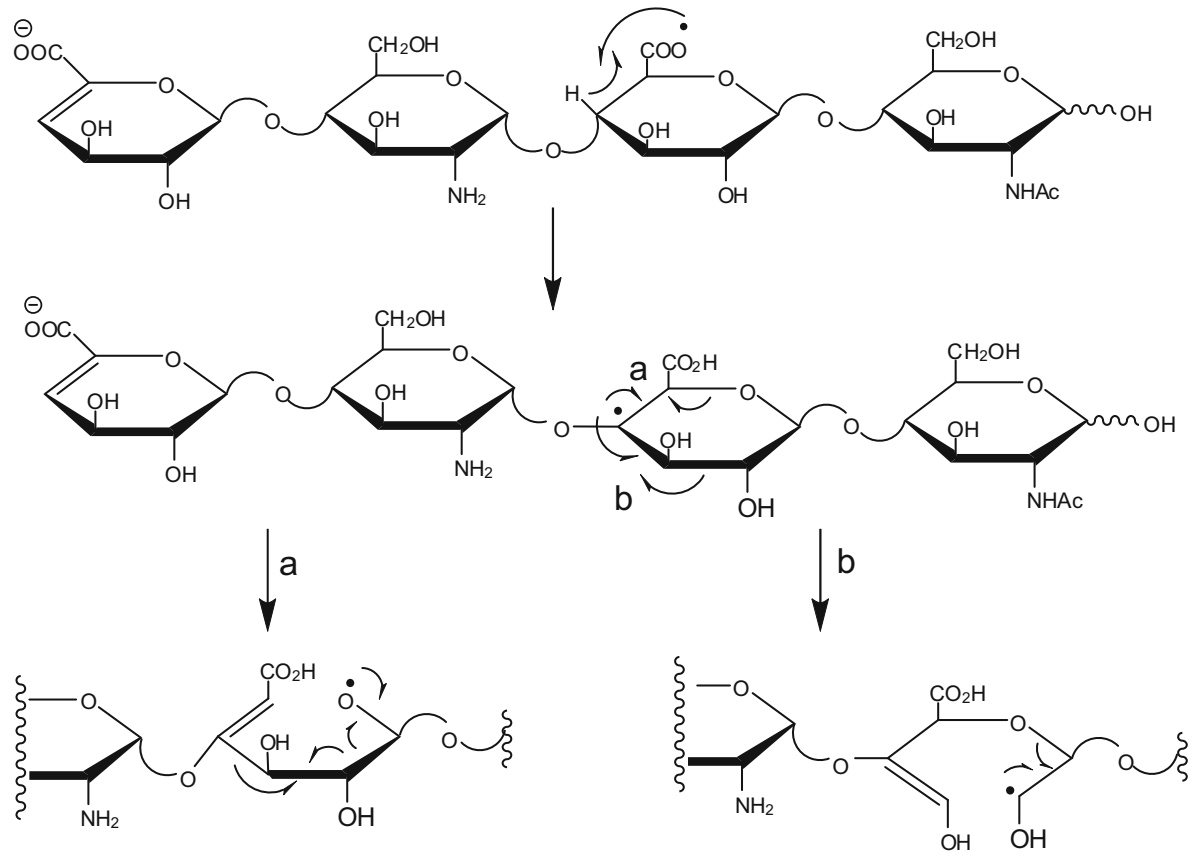

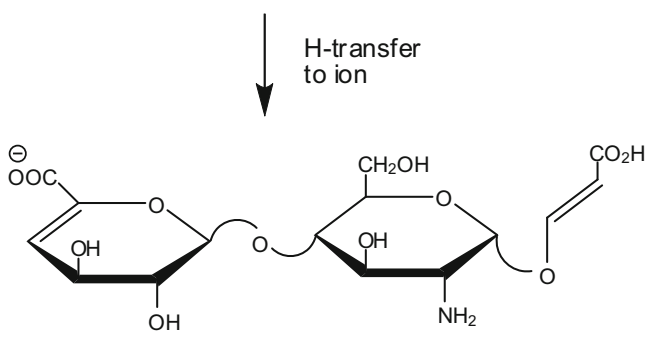

${ }^{3,5} \mathrm{~A}_{3}$ $\downarrow \begin{aligned} & \text { H-transfer } \\ & \text { to ion }\end{aligned}$

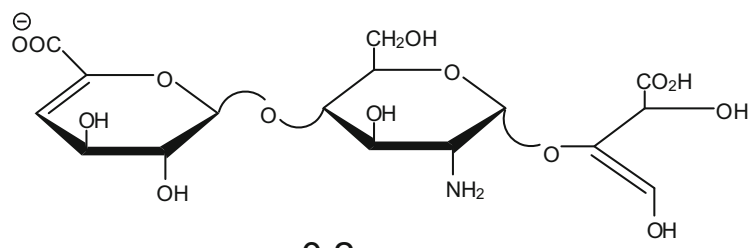

${ }^{0,2} \mathrm{~A}_{3}$

Scheme 4

40]. ${ }^{\circ}$ All ${ }^{\circ}$ of the ${ }^{\circ}$ fragments ${ }^{\circ}$ bserved in ${ }^{\circ}$ the ${ }^{\circ} \mathrm{CAD}^{\circ}$ spectrum are found in the IRMPD spectrum, and all the IRMPD products $^{\circ}$ are $^{\circ}$ present $^{\circ}$ in $^{\circ}$ the $^{\circ} \mathrm{EDD}^{\circ}$ spectrum $^{\circ}$ (Figure ${ }^{\circ} 2$, insets). We have found this to be generally true for all of the GAG tetrasaccharides examined to date, i.e., EDD gives the most comprehensive set of fragment ions, while the IRMPD products are a subset of the ions in the EDD spectrum, and the CAD products are a subset of the ions in the IRMPD spectrum. The EDD products that also occur in the IRMPD and CAD spectrum probably arise from direct fragmentation of the doublycharged precursor ion.

Electron activation of the precursor ion results in cleavage of every glycosidic bond and abundant crossring cleavages in the form of $\mathrm{A}$ ions, shown by dashed lines $^{\circ}$ in $^{\circ}$ the ${ }^{\circ}$ structure $^{\circ}$ shown $^{\circ}$ in ${ }^{\circ}$ the $^{\circ}$ inset $^{\circ}$ in $^{\circ}$ Figure $^{\circ} 2$ a. Product peak assignment was determined by comparison of the accurately measured masses with the theoretical product ions from glycosidic fragmentation of the tetrasaccharide. Other common cleavages such as the ${ }^{0,2} \mathrm{~A}_{\mathrm{n}}{ }^{2,5} \mathrm{~A}_{\mathrm{n}}$, and loss of $\mathrm{CO}_{2}$ were also identified in this manner. The $\mathrm{N}$-acetyl group on the reducing end of the tetrasaccharide increases the mass defect of the product ions containing the reducing end relative to fragments from the nonreducing end, allowing one to distinguish $\mathrm{A}, \mathrm{B}$, and $\mathrm{C}$ products from $\mathrm{X}, \mathrm{Y}$, and $\mathrm{Z}$ products. The remainder of the product ions were identified from their exact mass differences from $[\mathrm{M}-$ $2 \mathrm{H}]^{-}$, which establishes the elemental composition of the neutral loss. For example, the peak at $\mathrm{m} / z 452.099$ differs from the charge reduced species, $[\mathrm{M}-2 \mathrm{H}]^{-}$, by $262.085 u$. The calculated neutral loss for a ${ }^{0,2} \mathrm{~A}_{3}$ cleavage is $262.093 u$, while the calculated neutral loss for a ${ }^{2,4} \mathrm{X}_{2}$ cleavage is $262.069 u$. The exact mass calculation of the observed neutral loss suggests that this product ion is ${ }^{0,2} \mathrm{~A}_{3}$. This assignment was confirmed by comparison to the EDD spectrum of the closely related compound 2 (vide infra).

The EDD process can form a radical site by detachment of an electron from the doubly-charged precursor. Products from this singly-charged odd-electron ion can be either odd-electron or even-electron. The 


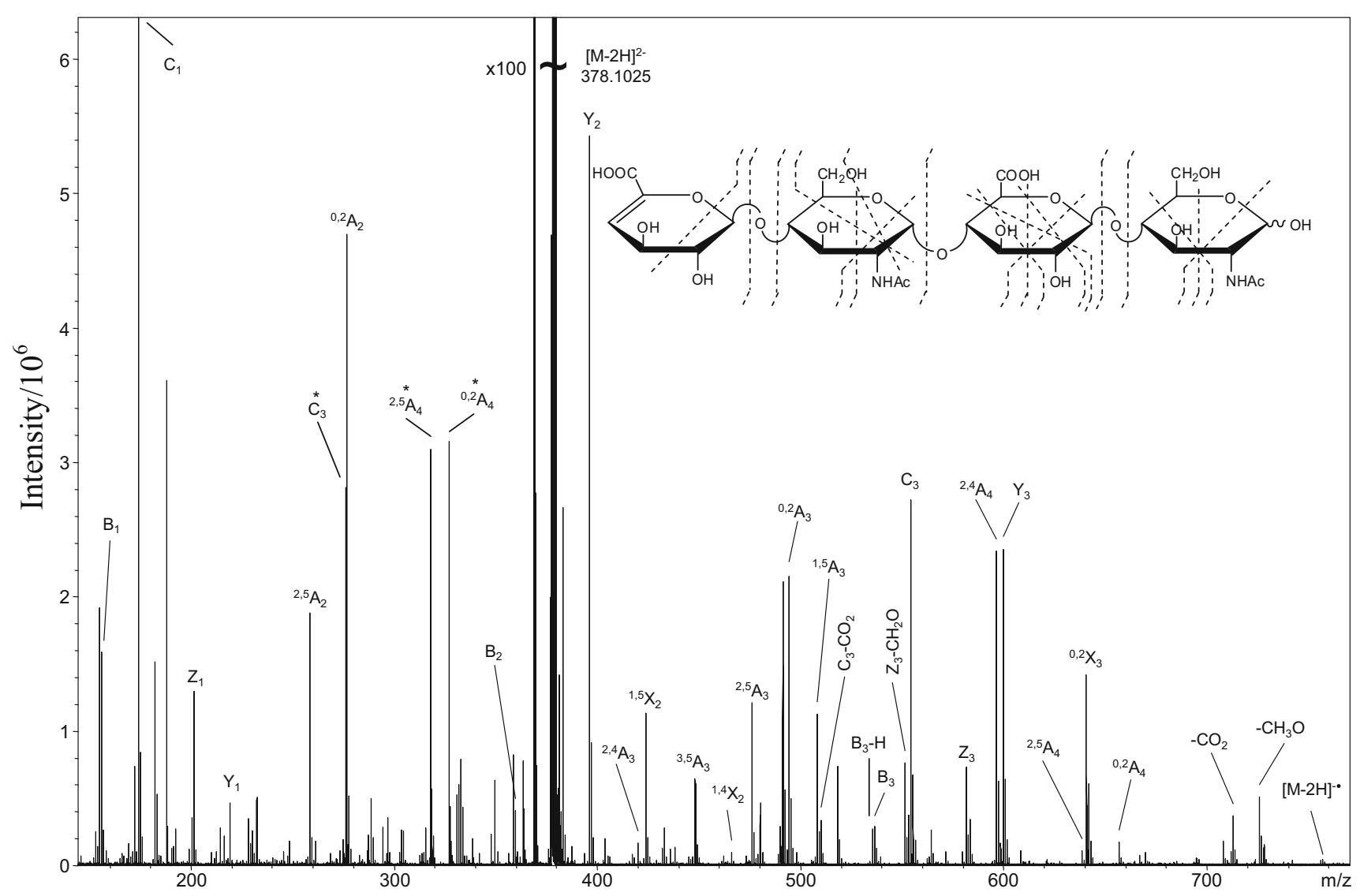

Figure 3. EDD mass spectrum of the $[\mathrm{M}-2 \mathrm{H}]^{2-}$ precursor ion of tetrasaccharide 2. $\mathrm{C}_{2}$ and $\mathrm{Z}_{2}$ are not assigned since the products overlap with the precursor ion. Doubly-charged product ions are indicated with an asterisk.

majority of the observed product ions are evenelectron ions. Odd-electron products include ions from the loss of small, stable neutral molecules $\left(\mathrm{M}^{-\cdot}\right.$ $\left.2 \mathrm{H}-\mathrm{CO}_{2}, \mathrm{M}^{-\cdot}-2 \mathrm{H}-\mathrm{CH}_{2} \mathrm{O}\right)$, as well as some glycosidic $\left(\mathrm{B}_{3}-\mathrm{H}, \mathrm{C}_{2}-\mathrm{H}\right)$ and cross-ring cleavages. Radical formation initially occurs at a site of negative charge. For 1, the two initial sites of negative charge are the carboxylic acid groups on the residues at the nonreducing end and the GlcA residue next to the reducing end. The large degree of fragmentation on the GlcA residue next to the reducing end indicates a preference for ion decomposition when the radical is located at this site. Radical site formation at the nonreducing end appears to form a stable species that is resistant to further fragmentation. Radical site formation at the GlcA carboxyl group can be followed by loss of $\mathrm{CO}_{2}$ to form the odd-electron product ion at $m / z$ 670.196. This species can undergo further radical-driven fragmentation of the glycosidic bond to produce the $\mathrm{C}_{2}-\mathrm{H}$ ion, as shown in the proposed mechanism in Scheme 2. Alternatively, the radical ion $\left[\mathrm{M}-2 \mathrm{H}-\mathrm{CO}_{2}\right]^{- \text {. }}$ can lose a hydrogen atom to form a more stable even electron ion, $\left[\mathrm{M}-2 \mathrm{H}-\mathrm{CO}_{2} \mathrm{H}\right]^{-}$.

There is also evidence of $\mathrm{H}$ atom transfer to the carboxyl radical from other positions in the glucuronic acid residue. One possibility is $\mathrm{H}$-atom transfer from the hydroxyl group on carbon C3 to the carboxyl radical, moving the radical site to the $\mathrm{C} 3$ oxygen atom, as shown in Scheme 3 . This radical site can promote ${ }^{3,5} \mathrm{~A}_{3}$ and ${ }^{0,2} \mathrm{~A}_{3}$ fragmentation. Alternatively, $\mathrm{H}$-atom transfer can come from C4 as shown in Scheme 4 . The resulting radical is stabilized by delocalization with the oxygen that forms the glycosidic bond to $\mathrm{C} 4$. H-atom transfer from carbon atoms in saccharide rings has been observed in collision induced electron detachment mass

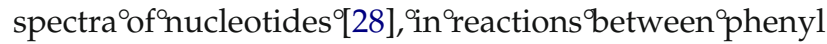
radical $^{\circ}$ cations $^{\circ}$ and ${ }^{\circ}$ ribose $^{\circ}[41],{ }^{\circ}$ and ${ }^{\circ}$ in ${ }^{\circ}$ the ${ }^{\circ} \mathrm{ECD}^{\circ}$ mass spectra ${ }^{\circ}$ of $^{\circ}$ glycopeptides ${ }^{\circ}[42] .{ }^{\circ}$ The $^{\circ}$ radical $^{\circ}$ site $^{\circ}$ at $^{\circ} \mathrm{C}^{\circ}{ }^{\circ} \mathrm{Can}$ promote ${ }^{3,5} \mathrm{~A}_{3}$ and ${ }^{0,2} \mathrm{~A}_{3}$ fragmentation as shown in Scheme 4 . The abundance of cross ring cleavage products from fragmentation in the second sugar residue from the reducing end in the EDD spectrum, and their absence in the CAD and IRMPD spectra, suggests radical-induced fragmentation of many of the bonds in this residue, which can be rationalized by mobility of the radical site via hydrogen rearrangement. The excess energy deposited into the ion during electron irradiation can supply the energy necessary to drive the hydrogen rearrangement.

Figure $^{\circ} 3^{\circ}$ shows $^{\circ}$ the $^{\circ}$ EDD $^{\circ}$ mass $^{\circ}$ spectrum $^{\circ}$ of ${ }^{\circ} \Delta \mathrm{UA}$ GlcNAc-GlcA-GlcNAc, 2, which differs from 1 by $\mathrm{N}$ acetylation in the GlcNAc residue next to the nonreduc- 


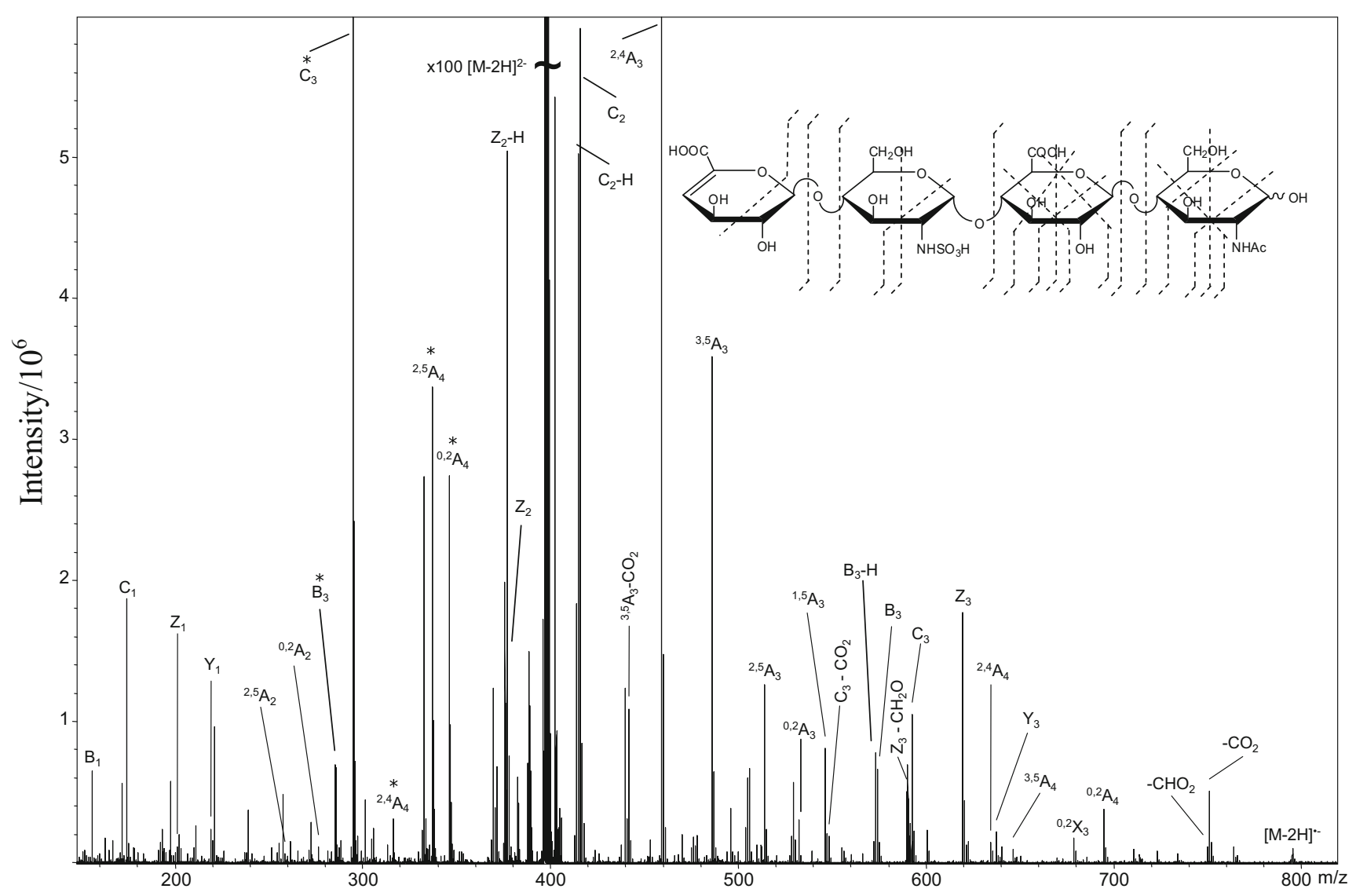

Figure 4. EDD mass spectrum of the $[\mathrm{M}-2 \mathrm{H}]^{2-}$ precursor ion of tetrasaccharide 3 . The $\mathrm{B}_{2}$ and $\mathrm{Y}_{2}$ product ions are not assigned as they overlap with the precursor ion. Doubly-charged product ions are indicated with an asterisk.

ing ${ }^{\circ}$ end..$^{\circ}$ The ${ }^{\circ}$ product ${ }^{\circ}$ ions ${ }^{\circ}$ from ${ }^{\circ}$ EDD $^{\circ}$ of ${ }^{\circ} 2,{ }^{\circ}$ Figure 3 , are similar in assignment and in abundance as observed products for EDD of 1. Some minor differences are evident. The $\mathrm{C}_{2}$ and $\mathrm{Z}_{2}$ ions are not assigned for EDD of 2 as they overlap with the precursor ion, and would be difficult to discern from the much more abundant remaining precursor. Some new cross-ring product ions are evident in the EDD mass spectrum of 2 . The ${ }^{2,4} \mathrm{~A}_{3}$ product ion present in the EDD spectrum of 2 is not assigned for 1, for if present, it would overlap with the $Z_{2}$ glycosidic cleavage for Structure 1 . The ${ }^{1,4} X_{2}$ product ion is observed as it does not overlap with the ${ }^{1,5} A_{3}$ cleavage, as it did for 1 . Aside from these minor differences, a majority of the assigned products are the same for the two related tetrasaccharides 1 and 2. The similarity of the EDD spectra for these two related compounds shows that observed fragmentation is not highly sensitive to small modifications of the sugar residues, and suggests regularity in the types of fragments that are observed.

Figure $^{\circ} 4^{\circ}$ shows $^{\circ}$ the $^{\circ}$ EDD $^{\circ}$ spectrum $^{\circ}$ of ${ }^{\circ}$ the ${ }^{\circ}$ sulfated GAG tetrasaccharide $\Delta \mathrm{UA}-\mathrm{GlcNSO}_{3}-\mathrm{GlcA}-\mathrm{GlcNAc}, 3$. Determining the sites of sulfation by MS/MS requires abundant glycosidic and cross-ring fragmentation without loss of $\mathrm{SO}_{3}$ from the labile sulfate group. The sulfate group provides an additional site of ionization for the tetrasaccharide. As sulfuric acid is more ionized in solution than a carboxylic acid, doubly-charged negative ions formed by ESI are expected to be ionized at the sulfate group and one of the carboxylic acid groups. Electron detachment is expected to occur principally at carboxylate, since the electron affinity of sulfate is considerably higher than the electron affinity of the carboxylate $\left(\mathrm{EA}\left(\mathrm{HSO}_{4}{ }^{-}\right) \approx 4.7 \mathrm{eV} ; \mathrm{EA}\left(\mathrm{DCO}_{2}{ }^{-}\right) \approx 3.5\right.$

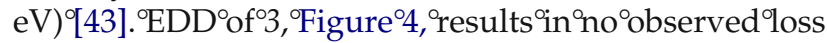
of $\mathrm{SO}_{3}$. Similar to EDD of 1 and 2, the odd-electron product ion $\left[\mathrm{M}-2 \mathrm{H}-\mathrm{CO}_{2}\right]^{-\cdot}$ is observed, indicating a preference for electron detachment from the carboxylate group rather than the sulfate, as it is expected that the sulfate radical would exhibit $\mathrm{SO}_{3}$ loss. The observed EDD $^{\circ}$ product $^{\circ}$ ions ${ }^{\circ}$ of $^{\circ} 3$ (Figure ${ }^{\circ} 4^{\circ}$ inset) ${ }^{\circ}$ are $^{\circ}$ similar $^{\circ}$ to those ions observed for 1 and 2 . The $B_{2}$ and $Y_{2}$ product ion are not assigned for 3 as they overlap with the precursor ion. In addition to the doubly-charged evenelectron ions observed in the EDD of 1 and 2, the doubly-charged product ion $B_{3}$ is also observed in the EDD of 3 . As with 1 and 2, there is substantial cross-ring cleavage in the residue next to the reducing end. ${ }^{0,2} \mathrm{~A}_{3}$ and ${ }^{3,5} \mathrm{~A}_{3}$ can be rationalized as resulting from hydrogen atom transfer from the hydroxyl group on C3 or from the hydrogen on C4, to the carboxyl radical at C5, followed by $\alpha$-cleavage, similar to the mechanisms for 1 


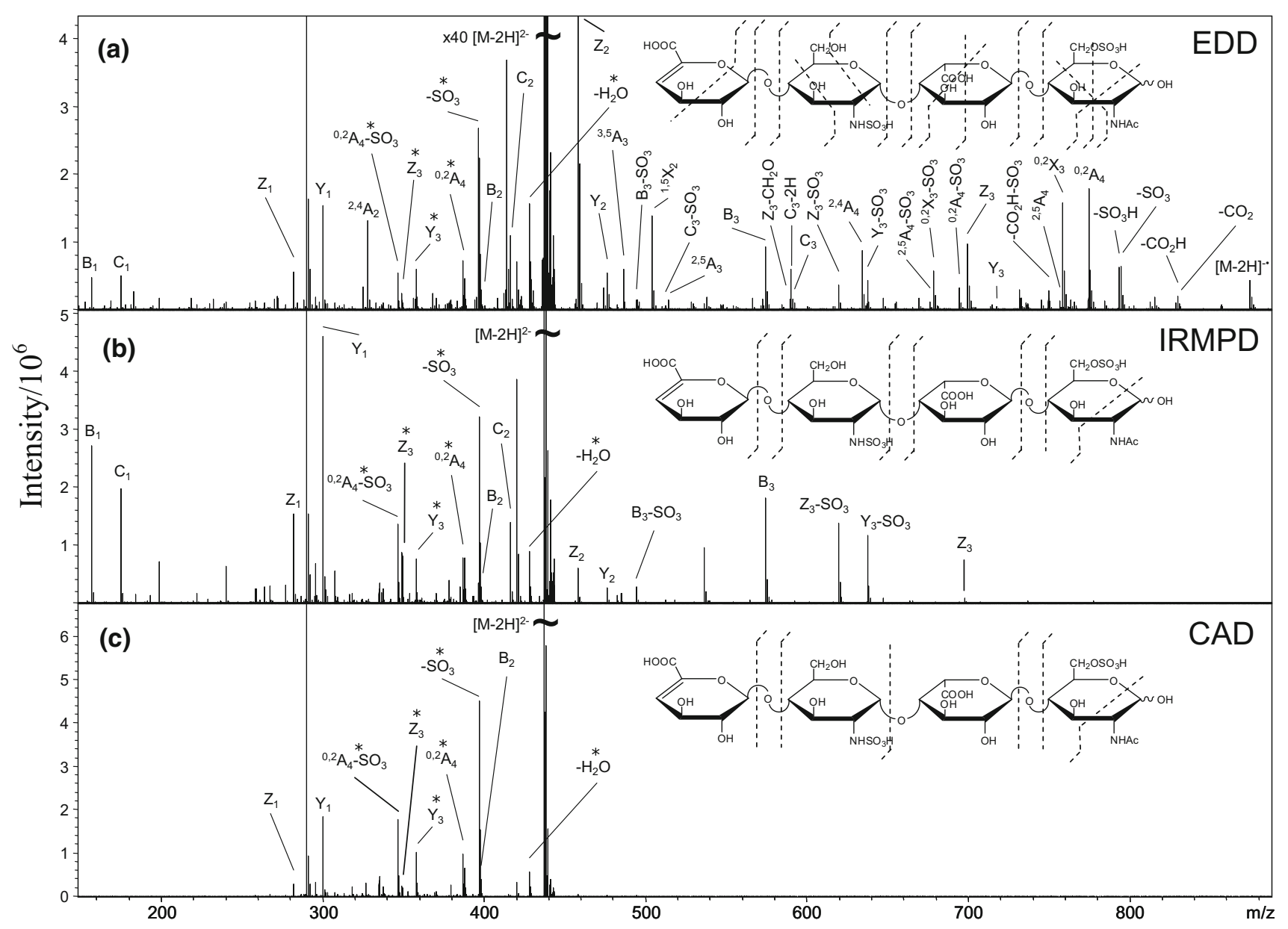

Figure 5. Tandem mass spectra of the $[\mathrm{M}-2 \mathrm{H}]^{2-}$ precursor ion of tetrasaccharide 4 , obtained by using (a) EDD, (b) IRMPD, and (c) CAD. Doubly-charged product ions are indicated with an asterisk.

shown in Schemes 3 and 4 . EDD of 3 leads to fragmentation of every glycosidic bond. The glycosidic products establish that the site of sulfation lies within the glucosamine residue next to the reducing end. This glucosamine residue has three possible sites of sulfation. The ${ }^{0,2} \mathrm{~A}_{2}$ and ${ }^{2,5} \mathrm{~A}_{2}$ cross-ring fragments place the sulfation on the amine group, establishing this as a GlcNS residue.

Tetrasaccharide 4, $\Delta \mathrm{UA}-\mathrm{GlcNSO}_{3}$-IdoA-GlcNAc-6$\mathrm{SO}_{4}$, contains two sulfate groups. In this case, the doubly-charged negative ion is expected to carry charge at the two sulfates, and EDD is expected to form a radical site at one of the sulfates. Dissociation of the [M $\left.-{ }^{\circ} \mathrm{H}\right]^{2-}$ precursor ${ }^{\circ}$ ion ${ }^{\circ}$ of 4 by $^{\circ} \mathrm{IRMPD}^{\circ}{ }^{\circ} \mathrm{r}^{\circ} \mathrm{CAD}^{\circ}$ (Figure $5 b^{\circ}$ or $^{\circ} \mathrm{C}^{\circ}$ respectively $)^{\circ}$ results $^{\circ}$ in $^{\circ}$ principally ${ }^{\circ}$ glycosidic cleavages. Some product ions are also found to lose $\mathrm{SO}_{3}$, and some glycosidic cleavages are only found with the loss of $\mathrm{SO}_{3}$. Although the residues that are sulfated can be determined from the glycosidic cleavage in the CAD and IRMPD spectra, identification of the sites of sulfation is difficult due to the limited amount of fragmentation that occurs by these methods of ion activation. In contrast, irradiation of the $[\mathrm{M}-2 \mathrm{H}]^{2-}$ precursor ion of 4 with $19 \mathrm{eV}$ electrons results in much more extensive fragmentation, as seen in the mass spectrum shown in Figure ${ }^{\circ}$ a. ${ }^{\circ}$ Predominantly ${ }^{\circ}$ singly-charged ${ }^{\circ}$ even-electron product ions are observed. Some doubly-charged product ions are observed such as $\left[\mathrm{M}-2 \mathrm{H}-\mathrm{SO}_{3}\right]^{2-}$ and ${ }^{0,2} \mathrm{~A}_{4}{ }^{2-}$, as well as the $\mathrm{Y}_{3}{ }^{2-}$ and $\mathrm{Z}_{3}{ }^{2-}$ glycosidic cleavages. Some product ions from the EDD fragmentation of 4 are observed both as product ions with two sulfates as well as with the loss of one molecule of $\mathrm{SO}_{3}$. For example, the $Z_{3}$ and $Y_{3}$ product ions are also observed as $\mathrm{Z}_{3}-\mathrm{SO}_{3}$ and $\mathrm{Y}_{3}-\mathrm{SO}_{3}$. The odd-electron product ions $\left[\mathrm{M}-2 \mathrm{H}-\mathrm{SO}_{3}\right]^{-\cdot}$ and $\left[\mathrm{M}-2 \mathrm{H}-\mathrm{CO}_{2}\right]^{-\cdot}$ are observed along with the even-electron product ions $[\mathrm{M}-2 \mathrm{H}-$ $\left.\mathrm{HSO}_{3}\right]^{-}$and $\left[\mathrm{M}-2 \mathrm{H}-\mathrm{HCO}_{2}\right]^{-}$. Doubly-charged negative ions of 4 formed by ESI are expected to be ionized at both sulfate groups. The presence of the [M $\left.2 \mathrm{H}-\mathrm{CO}_{2}\right]^{-\cdot}$ odd-electron product ion implies that either a carboxylate anion was formed during ionization or that the carboxyl radical was formed as a result of $\mathrm{H}$ atom transfer. The presence of a carboxyl radical on the IdoA residue next to the reducing end results in fragmentation similar to EDD of 1,2, and 3. Similar to $\mathrm{CAD}^{\circ}$ and $^{\circ} \mathrm{IRMPD}^{\circ}$ of $^{\circ} 1$ (Figure $^{\circ} 2 \mathrm{~b}^{\circ}$ and $^{\circ} \mathrm{c}$ ), ${ }^{\circ}$ all $^{\circ}$ of ${ }^{\circ}$ the product ions in the CAD spectrum are observed in the IRMPD spectrum, and all product ions in the IRMPD 
spectrum $^{\circ}$ are ${ }^{\circ}$ observed $^{\circ}{ }^{\circ}{ }^{\circ}$ the $^{\circ}$ EDD $^{\circ}$ spectrum $^{\circ}$ (Figure ${ }^{\circ}$, insets). Compared with IRMPD and CAD of 4 , the EDD mass spectrum of 4 exhibits peaks that result from cleavage of all glycosidic bonds as well as from abundant cross-ring cleavages. The cross-ring fragmentation of the reducing end sugar places the sulfate on C6 and

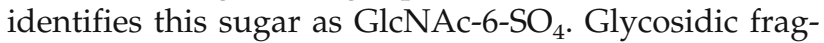
mentation identifies the sugar next to the nonreducing end as a sulfated GlcN sugar. The cross-ring fragmentation places the sulfate on either the $\mathrm{C} 2$ amino group or C6. The observed fragmentation cannot isolate the site of sulfation on this sugar.

The EDD spectra of the GAG tetrasaccharides exhibit a substantial number of fragment ions, many with low relative abundances. We find that the majority of these peaks appear reproducibly from spectrum to spectrum. The reproducibility of EDD fragmentation has been ascertained by comparing the spectra from identical samples acquired at an interval of one month (data not shown). The peaks are reproducible in both the massto-charge and abundance of the observed fragment ions. All previously identified product ions are present and no new product ions are observed. Even the unassigned, low abundance product ions are remarkably reproducible. The close match between EDD spectra collected at different times is reminiscent of the reproducibility of electron ionization mass spectra, and suggests that the product ions do not result from random cleavage of the molecule, but rather that products result from well-defined fragmentation pathways. These data suggest that EDD should be useful for characterizing the sites of modification in other GAG tetrasaccharides.

\section{Conclusions}

Irradiation of GAG tetrasaccharides with $19 \mathrm{eV}$ electrons results in predominantly even-electron product ions. EDD uses moderate energy electrons compared with the low-energy electrons used in ECD. These moderate energy electrons promote ion dissociation by direct fragmentation as well as via electron detachment. The abundance of glycosidic and cross-ring cleavage products by EDD will aid in the identification of this important class of compounds.

$\mathrm{H}$-atom transfer has been observed to occur between hydroxyl groups and carboxyl radicals. Since such atom transfers require proximity between the donor and acceptor sites, the particular hydroxyl group that participates in this rearrangement may be influenced by the stereochemistry of the C5 carbon. Future experiments on GAG epimers will determine whether the stereochemistry of the hexuronic acid C5 carbon influences EDD fragmentation in a manner that allows one to distinguish IdoA from GlcA. While we have confined these studies to tetrasaccharides, we believe that this approach should be extensible to longer GAG oligosaccharides.

\section{Acknowledgments}

The authors gratefully acknowledge financial support from the National Institutes of Health grant \#2R01-GM038060-16.

\section{References}

1. Perrimon, N.; Bernfield, M. Cellular Functions of Proteoglycans-an Overview. Semin. Cell. Dev. Biol. 2001, 12, 65-67.

2. Linhardt, R. J.; Toida, T. Role of Glycosaminoglycans in Cellular Communication. Acc. Chem. Res. 2004, 37, 431-438.

3. Fannon, M.; Forsten, K. E.; Nugent, M. A. Potentiation and Inhibition of bFGF Binding by Heparin: A Model for Regulation of Cellular Response. Biochemistry 2000, 39, 1434-1445.

4. Wu, Z. L.; Zhang, L.; Yabe, T.; Kuberan, B.; Beeler, D. L.; Love, A.; Rosenberg, R. D. The Involvement of Heparan Sulfate (HS) in FGF1/ HS/FGFR1 Signaling Complex. J. Biol. Chem. 2003, 278, 17121-17129.

5. Gotte, M. Syndecans in Inflammation. FASEB J. 2003, 17, 575-591.

6. Rabenstein, D. L. Heparin and Heparan Sulfate: Structure and Function. Nat. Prod. Rep. 2002, 19, 312-331.

7. Lindahl, U.; Kusche-Gullberg, M.; Kjellen, L. Regulated Diversity of Heparan Sulfate. J. Biol. Chem. 1998, 273, 24979-24982.

8. Turnbull, J.; Powell, A.; Guimond, S. Heparan Sulfate: Decoding a Dynamic Multifunctional Cell Regulator. Trends Cell. Biol. 2001, 11, 75-82.

9. Salmivirta, M.; Lidholt, K.; Lindahl, U. Heparan Sulfate: A Piece of Information. FASEB J. 1996, 10, 1270-1279.

10. Naggar, E. F.; Costello, C. E.; Zaia, J. Competing Fragmentation Processes in Tandem Mass Spectrometry of Heparin-Like Glycosaminoglycans. J. Am. Soc. Mass Spectrom. 2004, 15, 1534-1544.

11. Carr, S. A.; Reinhold, V. N. Structural Characterization of Sulfated Glycosaminoglycans by Fast Atom Bombardment Mass-SpectrometryApplication to Chondroitin Sulfate. J. Carb. Chem. 1984, 3, 381-401.

12. Reinhold, V. N.; Carr, S. A.; Green, B. N.; Petitou, M.; Choay, J.; Sinay, P. Structural Characterization of Sulfated Glycosaminoglycans by FastAtom-Bombardment Mass-Spectrometry-Application to Heparin Fragments Prepared by Chemical Synthesis. Carbohydr. Res. 1987, 161, 305-313.

13. Takagaki, K.; Kojima, K.; Majima, M.; Nakamura, T.; Kato, I.; Endo, M. Ion-Spray Mass-Spectrometric Analysis of Glycosaminoglycan Oligosaccharides. Glycoconj. J. 1992, 9, 174-179.

14. Dai, Y.; Whittal, R. M.; Bridges, C. A.; Isogai, Y.; Hindsgaul, O.; Li, L. Matrix-Assisted Laser Desorption Ionization Mass Spectrometry for the Analysis of Monosulfated Oligosaccharides. Carbohydr. Res. 1997, 304, $1-9$.

15. Juhasz, P.; Biemann, K. Utility of Noncovalent Complexes in the Matrix-Assisted Laser Desorption Ionization Mass Spectrometry of Heparin-Derived Oligosaccharides. Carbohydr. Res. 1995, 270, 131-147.

16. Lo-Guidice, J.-M.; Herz, H.; Lamblin, G.; Plancke, Y.; Roussel, P.; Lhermitte, M. Structures of Sulfated Oligosaccharides Isolated from the Respiratory Mucins of a Nonsecretor $(\mathrm{O}$, Lea $+\mathrm{b}-)$ Patient Suffering from Chronic Bronchitis. Glycoconj. J. 1997, 14, 113-125.

17. Schiller, J.; Arnhold, J.; Benard, S.; Reichl, S.; Arnold, K. Cartilage Degradation by Hyaluronate Lyase and Chondroitin ABC Lyase: A MALDI-TOF Mass Spectrometric Study. Carbohydr. Res. 1999, 318, $116-122$.

18. Zaia, J.; Costello, C. E. Tandem Mass Spectrometry of Sulfated HeparinLike Glycosaminoglycan Oligosaccharides. Anal. Chem. 2003, 75, 24452455.

19. Viseux, N.; de Hoffmann, E.; Domon, B. Structural Assignment of Permethylated Oligosaccharide Subunits Using Sequential Tandem Mass Spectrometry. Anal. Chem. 1998, 70, 4951-4959.

20. Saad, O. M.; Leary, J. A. Heparin Sequencing Using Enzymatic Digestion and ESI-MS with HOST: A Heparin/HS Oligosaccharide Sequencing Tool. Anal. Chem. 2005, 77, 5902-5911.

21. Zamfir, A.; Seidler, D. G.; Kresse, H.; Peter-Katalinic, J. Structural Characterization of Chondroitin/Dermatan Sulfate Oligosaccharides from Bovine Aorta by Capillary Electrophoresis and Electrospray Ionization Quadrupole Time-of-Flight Tandem Mass Spectrometry. Rapid Commun. Mass Spectrom. 2002, 16, 2015-2024

22. Zubarev, R. A.; Kelleher, N. L.; McLafferty, F. W. Electron Capture Dissociation of Multiply Charged Protein Cations. A Nonergodic Process. J. Am. Chem. Soc. 1998, 120, 3265-3266.

23. Zubarev, R. A.; Haselmann, K. F.; Budnik, B.; Kjeldsen, F.; Jensen, F.Towards an Understanding of the Mechanism of Electron-Capture Dissociation: A Historical Perspective and Modern Ideas. Eur. J. Mass Spectrom. 2002, 8, 337-349.

24. Stensballe, A.; Jensen, O. N.; Olsen, J. V.; Haselmann, K. F.; Zubarev, R. A. Electron Capture Dissociation of Singly and Multiply Phosphorylated Peptides. Rapid Commun. Mass Spectrom. 2000, 14, 1793-1800.

25. Hakansson, K.; Cooper, H. J.; Emmett, M. R.; Costello, C. E.; Marshall, A. G.; Nilsson, C. L. Electron Capture Dissociation and Infrared Multiphoton Dissociation MS/MS of an N-Glycosylated Tryptic Peptide to Yield Complementary Sequence Information. Anal. Chem. 2001, 73, 4530-4536.

26. Budnik, B. A.; Haselmann, K. F.; Elkin, Y. N.; Gorbach, V. I.; Zubarev R. A. Applications of Electron-Ion Dissociation Reactions for Analysis of 
Polycationic Chitooligosaccharides in Fourier Transform Mass Spectrometry. Anal. Chem. 2003, 75, 5994.

27. Zubarev, R. A. Reactions of Polypeptide Ions with Electrons in the Gas Phase. Mass Spectrom. Rev. 2003, 22, 57.

28. Liu, B.; Hvelplund, P.; Nielsen, S. B.; Tomita, S. Electron Loss and Dissociation in High Energy Collisions Between Multiply Charged Oligonucleotide Anions and Noble Gases. Int. J. Mass Spectrom. 2003, 230, 19.

29. Anusiewicz, I.; Jasionowski, M.; Skurski, P.; Simons, J. Backbone and Side-Chain Cleavages in Electron Detachment Dissociation (EDD). J. Phys. Chem. A. 2005, 109, 11332.

30. Budnik, B. A.; Haselmann, K. F.; Zubarev, R. A. Electron Detachment Dissociation of Peptide Dianions: An Electron-Hole Recombination Phenomenon. Chem. Phys. Lett. 2001, 342, 299-302.

31. Cooper, H. J.; Hakansson, K.; Marshall, A. G. The Role of Electron Capture Dissociation in Biomolecular Analysis. Mass Spectrom. Rev. 2005, 24, 201-222.

32. Kjeldsen, F.; Silivra, O. A.; Ivonin, I. A.; Haselmann, K. F.; Gorshkov, M. Zubarev, R. A.C $\alpha-C$ Backbone Fragmentation Dominates in Electron Detachment Dissociation of Gas-Phase Polypeptide Polyanions. Chem. Eur. J. 2005, 11, 1803-1812.

33. McFarland, M. A.; Marshall, A. G.; Hendrickson, C. L.; Nilsson, C. L.; Fredman, P.; Mansson, J. E. Structural Characterization of the GM1 Ganglioside by Infrared Multiphoton Dissociation/Electron Capture Dissociation and Electron Detachment Dissociation Electrospray Ionization FT-ICR MS/MS. J. Am. Soc. Mass Spectrom. 2005, 16, 752.

34. Yang, J.; Mo, J.; Adamson, J. T.; Hakansson, K. Characterization of Oligodeoxynucleotides by Electron Detachment Dissociation Fourier Transform Ion Cyclotron Resonance Mass Spectrometry. Anal. Chem. 2005, 77, 1876-1882.
35. Pervin, A.; Gallo, C.; Jandik, K. A.; Han, X.-J.; Linhardt, R. J. Preparation and Structural Characterization of Large Heparin-Derived Oligosaccharides. Glycobiology 1995, 5, 83-95.

36. Munoz, E.; Xu, D.; Avci, F.; Kemp, M.; Liu, J.; Linhardt, R. J. Enzymatic Synthesis of Heparin Related Polysaccharides on Sensor Chips: Rapid Screening of Heparin-Protein Interactions. Biochem. Biophys. Res. Commun. 2006, 339, 597-602.

37. Domon, B.; Costello, C. E. A Systematic Nomenclature for Carbohydrate Fragmentations in FAB-MS/MS Spectra of Glycoconjugates. Glycoconj. J. 1988, 5, 397-409.

38. Gorshkov, M. V.; Masselon, C. D.; Nikolaev, E. N.; Udseth, H. R.; PasaTolic, L.; Smith, R. D. Considerations for Electron Capture Dissociation Efficiency in FTICR Mass Spectrometry. Int. J. Mass Spectrom. 2004, 234, 131

39. Zaia, J.: McClellan, J. E.; Costello, C. E. Tandem Mass Spectrometric Determination of the 4S/6S Sulfation Sequence in Chondroitin Sulfate Oligosaccharides. Anal. Chem. 2001, 73, 6030-6039.

40. Saad, O. M.; Leary, J. A. Delineating Mechanisms of Dissociation for Isomeric Heparin Disaccharides Using Isotope Labeling and Ion Trap Tandem Mass Spectrometry. J. Am. Soc. Mass Spectrom. 2004, 15, 1274-1286.

41. Ramirez-Arizmendi, L. E.; Heidbrink, J. L.; Guler, L. P.; Kenttamaa, H. I. Reactivity of Substituted Charged Phenyl Radicals Toward Components of Nucleic Acids. J. Am. Chem. Soc. 2003, 125, 2272.

42. Mormann, M.; Paulsen, H.; Peter-Katalinic, J.Electron Capture Dissociation of O-Glycosylated Peptides: Radical Site-Induced Fragmentation of Glycosidic Bonds. Eur. J. Mass Spectrom. 2005, 11, 497.

43. Bartmess, J. ENegative Ion Energetics Data: Linstrom, P. J: Mallard, W. G., EdS.; National Institute of Standards and Technology: Gaithersburg, MD, 2005; p 20899. 